\title{
Formação e prática pedagógica de professores de geografia para a inclusão de estudantes surdos
}

\author{
Formation and pedagogical practice of geography teachers for the \\ inclusion of deaf students
}

\author{
Fernanda Santos Pena'; Adriany de Ávila Melo Sampaio"
}

\section{RESUMO}

Para a inclusão dos estudantes surdos nas escolas comuns é imprescindível a formação docente adequada, assim como práticas pedagógicas que contemplem as necessidades educacionais destes estudantes. Esse artigo teve como objetivo analisar a formação de professores de Geografia e as suas práticas para estudantes surdos do Ensino Fundamental ( $6^{\circ}$ ao $9^{\circ}$ ano) em escolas municipais de Uberlândia/MG. Foi utilizada a pesquisa qualitativa, por meio de dois instrumentos de coleta de dados: a entrevista semiestruturada e a observação. Buscou-se conhecer, em especial, a formação dos profissionais que atuam com os estudantes surdos, as metodologias e os materiais didáticos de Geografia utilizados, a eficiência dos recursos visuais, os apoios oferecidos para a melhoria da prática pedagógica, assim como as demandas para que os estudantes surdos tenham maior sucesso escolar. A pesquisa concluiu que a maioria dos professores de Geografia não é capacitada para lecionar para estudantes surdos e não está realizando um ensino inclusivo. O ensino de Geografia deve ser recorrente às práticas pedagógicas baseadas na visualização, pois os recursos visuais facilitam o aprendizado dos surdos e podem fazer a ponte entre os conhecimentos cotidianos e científicos. Os artefatos tecnológicos, a Internet, os mapas conceituais, o uso de imagens, de mapas e maquetes, assim como o Trabalho de Campo são promissores, sendo imprescindível a utilização da Libras.

Palavras-chave: Formação Docente; Inclusão Escolar; Libras; Metodologias de Ensino

\section{ABSTRACT}

For the inclusion of deaf students in common schools is indispensable a correct formation docent, such as pedagogical practices that take into account the educational needs of these students are essential. This article has the aim to analyze the formation of Geography teachers and their practices for deaf students from Elementary School (6th to 9th grade) in municipal schools in Uberlândia / MG. The qualitative research was used, through two instruments of data collection: the interview and the observation. It was sought to know, in particular, the training of professionals who work with deaf students, the methodologies and didactic materials of Geography used, the efficiency of the visual resources, the supports offered for the improvement of the pedagogical practice, as well as the demands for that deaf students are more successful in school. The survey found that most Geography teachers are not be able to teach for deaf students and are not accomplish an inclusive education. The teaching of Geography should be recurrent to pedagogical practices based on visualization, since the

'Doutoranda em Geografia pela Universidade Federal de Uberlândia-UFU. E-mail: fernandapena87@yahoo.com.br ORCID: https://orcid.org/0000-0003-2931-2182

"Professora do Instituto de Geografia e do Programa de Pós Graduação em Geografia da UFU E-mail: adrianyavila@gmail.com ORCID: https://orcid.org/0000-0003-4428-8395 
visual resources facilitate the learning of the deaf and can make a bridge between the daily scientific knowledge. Technological artifacts, the Internet, concept maps, use of images, maps and models, as well as fieldwork are promising, and the use of Libras is essential.

Keywords: Formation of Teachers; Libras; School Inclusion; Teaching Methods

\section{INTRODUÇÃO}

A Geografia é um conteúdo curricular capaz de formar para a cidadania, pois busca conhecer e explicar as múltiplas interações entre a sociedade e a natureza. Sendo ela um componente presente na escola básica, possibilita ao estudante descobrir e analisar sua realidade e os problemas de sua época e lugar, dando-Ihes condições de autonomia, de criatividade e de criticidade. Quando se almeja que o estudante seja incluído na escola e na sociedade, a Geografia é uma importante aliada.

A inclusão escolar de estudantes surdos nas escolas comuns originou o desafio de se realizarem metodologias de Geografia que atendam a este público. De acordo com pesquisadores da área, estudantes surdos possuem o canal visual como principal receptor de informações, sendo necessário explorar materiais concretos e imagéticos para um melhor aprendizado. Para isto, a formação docente é primordial, pois a qualificação profissional irá direcionar o professor de Geografia mediante sua prática.

Nesse sentido, o ensino de Geografia inclusivo perpassa pela formação adequada do professor, sendo que a qualidade de sua mediação pedagógica dependerá de sua formação. Sabendo-se da importância dessa formação e da adoção de metodologias de ensino de Geografia significativas para os estudantes surdos, esta pesquisa teve como objetivo analisar o ensino de Geografia para estes estudantes no Ensino Fundamental ( $6^{\circ}$ ao $9^{\circ}$ ano). Durante a pesquisa, conheceu-se o processo de inclusão e identificaram-se as concepções e as práticas pedagógicas de professores de Geografia, em sete escolas municipais de Uberlândia/MG. 
Foi utilizada a pesquisa qualitativa, por meio de dois tipos de coleta de dados: a entrevista semiestruturada em sete escolas, com 11 professores pesquisados, e a observação de aulas de Geografia em uma escola com 15 estudantes surdos. Buscou-se conhecer, em especial, a formação dos profissionais que atuam com estes estudantes, as metodologias e os materiais didáticos de Geografia utilizados, a eficiência dos recursos visuais, os apoios oferecidos para a melhoria da prática pedagógica dos professores de Geografia, assim como as demandas para que os estudantes surdos tenham maior sucesso escolar.

Este artigo discute os resultados da pesquisa, tendo como base o levantamento bibliográfico dos temas abordados. Primeiramente, realiza-se uma discussão sobre a formação dos professores de Geografia para a inclusão dos estudantes com deficiência nas escolas comuns, enfatizando-se o caso dos surdos. Em seguida, são realizadas reflexões sobre a educação dos surdos e a forma como os mesmos podem aprender melhor os conteúdos de Geografia. Por fim, são apresentados e discutidos os resultados obtidos com as entrevistas e a observação das aulas de Geografia.

\section{A FORMAÇÃO DOCENTE EM GEOGRAFIA PARA A INCLUSÃO ESCOLAR}

Para que ocorra um ensino de Geografia inclusivo é fundamental a formação adequada do professor, pois a qualidade de sua mediação dependerá de sua formação profissional. Cavalcanti (2003) destaca que o processo de formação é um processo contínuo, tendo como princípio a articulação ensinopesquisa e ação-reflexão, assim como a reflexão crítica do professor.

Esse processo de formação passa por dois momentos: a habilitação formal, também conhecida como inicial, e a formação continuada. A primeira ocorre durante o curso de licenciatura, possuindo suas características associadas à 
instituição onde é realizado. Já a segunda realiza-se permanentemente, decorrente do ato de se pensar e teorizar a própria prática (CALLAI, 1999).

O processo de formação do professor de Geografia e suas experiências de vida irão constituir os seus saberes profissionais. Tardif (2000) afirma que boa parte do que os professores sabem sobre o ensino, sobre os papéis do professor e sobre como ensinar provém de sua própria história de vida e, sobretudo, de sua história de vida escolar. Muitos professores, mesmo após sua passagem pelos cursos de licenciatura, não modificam suas crenças anteriores sobre o ensino, pois carregam consigo sua cultura escolar anterior.

Ainda se tratando dos saberes profissionais dos professores, devem ser levados em conta os conhecimentos disciplinares adquiridos na universidade, assim como os conhecimentos didáticos e pedagógicos. Há também os conhecimentos curriculares, presentes nos programas, guias e manuais escolares, bem como os conhecimentos pautados em sua experiência de trabalho e na experiência de certos professores (TARDIF, 2000).

De acordo com o mesmo autor, todos esses conhecimentos serão úteis para que o professor de Geografia atinja seus inúmeros objetivos em sala de aula. Dentre eles, observam-se os seguintes: controlar o grupo de alunos; buscar sua motivação; levá-lo a se concentrar em determinada tarefa ao mesmo tempo em que dão uma atenção particular a certos alunos da turma; organizar as atividades de aprendizagem; acompanhar a evolução da atividade; dar explicações e fazer com que os alunos compreendam e aprendam. Desse modo, o trabalho em sala de aula demanda inúmeras habilidades e competências.

Quando há a presença de estudantes com deficiência em sala de aula, o professor necessita adquirir ou empregar mais habilidades, pois esses alunos exigem um atendimento especial, de modo que não sejam excluídos das atividades realizadas.

Rodrigues (2006) afirma que a aquisição de competências para a gestão inclusiva de uma classe só poderá ser adquirida por meio de uma prática 
continuada, reflexiva e coletiva. O desenvolvimento dessas competências para a Educação Inclusiva deve, a seu ver, passar por uma fase de sensibilização na formação inicial e ser plenamente assumido ao longo de uma prática em serviço. Enfatiza que deve ocorrer dessa forma porque, na Educação Inclusiva, o comprometimento com a educação de todos os alunos é de toda a escola.

Michels (2006) destaca dois tipos de professores que trabalham com alunos que apresentam deficiência: os capacitados e os especializados. As competências a serem desenvolvidas nos chamados professores capacitados, que atuam na sala de aula comum, são apresentadas no artigo 18 (BRASIL, 2001):

$\S 1^{\circ}$ - São considerados professores capacitados para atuar em classes comuns com alunos que apresentam necessidades educacionais especiais aqueles que comprovem que, em sua formação, de nível médio ou superior, foram incluídos conteúdos sobre educação especial adequados ao desenvolvimento de competências e valores para:

I - perceber as necessidades educacionais especiais dos alunos e valorizar a educação inclusiva;

II - flexibilizar a ação pedagógica nas diferentes áreas de conhecimento de modo adequado às necessidades especiais de aprendizagem;

III - avaliar continuamente a eficácia do processo educativo para o atendimento de necessidades educacionais especiais;

IV - atuar em equipe, inclusive com professores especializados em educação especial.

Observa-se que a formação dos professores capacitados deve ocorrer por meio de oferecimento de disciplinas e cursos que venham a contemplar as discussões sobre a educação de alunos com deficiência. A sua formação também deve desenvolver competências para executar atividades diretamente com os esses alunos, assim como aprender a trabalhar em equipe, pois os professores especializados são os responsáveis por adaptar as atividades, assim como oferecer apoio constante.

Para que ocorra a inclusão escolar dos alunos com deficiência visual, por exemplo, a utilização de recursos didáticos adaptados torna-se indispensável. Para o aluno cego, deve ocorrer a transcrição do material escrito para o Braille 
(não necessariamente realizada pelo professor regente), e/ou realizar a leitura oral. Para os alunos com baixa visão, ampliações do livro didático, textos, mapas, figuras, provas e atividades são fundamentais. O costume de escrever no quadro negro já não é mais eficaz, visto que alguns desses alunos não conseguem visualizar o conteúdo. Ao professor de Geografia, caberá pesquisar, exigir da instituição ou elaborar materiais adaptados (em alto relevo, com cores contrastantes, dentre outros) que atendam a todos os alunos.

Os alunos com deficiência intelectual e transtornos globais do desenvolvimento também requerem práticas diferenciadas. Esses alunos irão acompanhar o conteúdo escolar de maneira distinta, pois precisam de tempo maior para compreendê-lo, assim como possuem o direito de um tempo maior para a realização das atividades avaliativas. Há casos em que esses alunos são semi-analfabetos, em que apenas copiam o que o professor solicita, sem conseguir fazer a leitura e interpretação do português escrito (são os chamados alunos "copistas"). Tais alunos encontram-se nos diversos anos do Ensino Básico, pois se considera a sua evolução em particular, de modo não comparativo com os demais alunos.

Muitos professores não concordam com essa forma de progressão dos alunos com deficiência intelectual, afirmando que é impossível ensinar para um aluno que não consegue ler nem escrever. Entretanto, deve-se considerar que os alunos não aprendem apenas por meio da leitura e escrita, mas também participando das demais atividades na sala de aula. Diante dessa situação, exigem-se do professor habilidades distintas, na tentativa de fazer com que o aluno aprenda de modo diferenciado, mesmo que seja apenas uma pequena parcela do conteúdo ministrado. Para isso, as potencialidades e dificuldades de cada estudante, com suas características e conhecimentos individuais, devem ser conhecidas e consideradas.

Nas turmas com estudantes surdos, o professor de Geografia sentirá maiores dificuldades com relação à comunicação, pois a maioria dos professores 
não domina a Libras (Língua Brasileira de Sinais). Devido à falta de formação docente para atuar na escolarização de alunos surdos, promulgou-se o Decreto n 5.626, de 22 de dezembro de 2005. Em seu Capítulo II, tal decreto dispõe sobre a inclusão da Libras como disciplina curricular obrigatória nos cursos de formação de professores.

Art. $3^{\circ}$. A Libras deve ser inserida como disciplina curricular obrigatória nos cursos de formação de professores para o exercício do magistério, em nível médio e superior, e nos cursos de Fonoaudiologia, de instituições de ensino, públicas e privadas, do sistema federal de ensino e dos sistemas de ensino dos Estados, do Distrito Federal e dos Municípios.

$\S 1^{\circ}$ Todos os cursos de licenciatura, nas diferentes áreas do conhecimento, o curso normal de nível médio, o curso normal superior, o curso de Pedagogia e o curso de Educação Especial são considerados cursos de formação de professores e profissionais da educação para o exercício do magistério. (BRASIL, 2005)

Esse decreto representou um grande avanço para a escolarização das pessoas surdas e também para o fortalecimento e reconhecimento da Libras como língua natural da comunidade surda brasileira.

Considerando que, em 2005, houve a inclusão da Libras como disciplina curricular obrigatória nos cursos de formação de professores, observa-se que apenas no ano de 2010 a Universidade Federal de Uberlândia, não diferentemente de outras instituições, exigiu que todos os alunos das licenciaturas cursassem a disciplina.

Diante de tal constatação, Pena (2010) realizou nessa universidade uma pesquisa que teve como um de seus objetivos conhecer a formação inicial de professores de Geografia na perspectiva da inclusão de estudantes surdos, por meio de questionários aplicados para os licenciandos do último período do curso de Geografia, os quais cursavam a disciplina de Libras.

Segundo Pena (2010), constatou-se que, durante o curso de Licenciatura em Geografia, a maioria dos graduandos não cursou disciplinas que abordaram o tema Inclusão Escolar, nem obteve conhecimentos sobre metodologias e materiais didáticos direcionados para estudantes surdos. 
Com relação à disciplina de Libras, a mesma autora afirma que os graduandos a consideraram pouco importante para a sua formação, visto que os mesmos estão cientes de que a carga horária em que a disciplina é oferecida (sessenta horas) não possibilita uma aprendizagem significativa da Libras e/ou de conceitos mais aprofundados sobre a surdez.

Os graduandos também fizeram apontamentos sobre o que consideravam importante para a melhoria da formação docente para a inclusão de alunos surdos, durante a licenciatura. Dentre eles, verificam-se os seguintes: inserção da Libras em períodos anteriores, com maior carga horária; oferecimento de uma disciplina específica de Libras para a Geografia, visto que na disciplina são matriculados alunos de inúmeros cursos, e a redução do número de graduandos por turma nessa disciplina; elaboração de materiais didáticos e métodos de ensino de Geografia para alunos surdos; realização de trabalhos de campo, onde os graduandos poderiam vivenciar e ou observar a cultura surda, e ter contatos com mais pessoas surdas (PENA, 2010).

Por meio do estudo de Pena (2010) percebe-se que a formação docente em Geografia para estudantes surdos precisa ser alvo de críticas e transformações. Se apenas nos últimos anos tem-se enfatizado a inclusão de alunos com deficiência na escola comum (onde alunos com e sem deficiência estudam juntos), em todos os âmbitos também se verifica uma necessidade urgente de instrumentalizar professores já atuantes nesta escola, para a inclusão de alunos com deficiência e, especialmente, alunos surdos.

Uma das alternativas para a melhoria da formação docente é a modificação da cultura das instituições formadoras e dos locais de trabalho dos professores, para possibilitar o desenvolvimento da habilidade de refletir, formar hábitos de pesquisa, de experimentação, de verificação, análise e problematização da própria prática (ROSA, 2006).

O fato de os professores sentirem-se "abandonados", e sem um espaço-tempo para dar vazão aos seus sentimentos e questionamentos sobre a inclusão, vem acarretando sentimentos de incapacidade e despreparo ao trabalharem 
com o aluno com necessidades educacionais especiais (DUEK; NAUJORKS, 2007, p.49).

Além dos cursos de formação continuada, promover atividades de reflexão sistemática e coletiva pelos professores sobre o seu trabalho docente, disponibilizando tempo e espaço, praticamente inexistentes na atual estruturação escolar, também é fundamental para a formação docente.

\section{A AQUISIÇÃO DE CONHECIMENTO PELO ESTUDANTE SURDO E A GEOGRAFIA}

Com a ampliação constante da inclusão escolar de estudantes surdos nas escolas comuns, é necessário pensar sobre as práticas pedagógicas que estão sendo realizadas. Primordialmente, precisa-se extinguir o ouvintismo, ou seja, a hegemonia da cultura ouvinte sobre a cultura surda, muito presente nas escolas. A cultura surda origina-se da língua de sinais, da experiência de mundo própria das pessoas surdas, e seu principal canal é visuo-gestual. Por parte das pessoas surdas, há a existência de uma forma peculiar de se relacionar com o mundo, sendo denominada por muitos de cultura surda.

No ouvintismo, os ouvintes decidem pelos surdos, querem inseri-los na cultura ouvinte e não respeitam suas identidades, ou seja, quer se fazer do surdo um ouvinte.

Conhecer os Estudos Surdos em Educação pode ser fundamental para se realizar práticas pedagógicas de acordo com as necessidades e perspectivas da surdez. Os Estudos Surdos associam-se a um campo investigativo que tem suas raízes nos Estudos Culturais, pois se destacam as questões das culturas, das políticas, das identidades, dos processos de formação dos povos surdos, das práticas pedagógicas, das diferenças e das relações de poderes e saberes surdos (REIS, 2006).

Perlin (1998, p.53), estudiosa dos Estudos Surdos, afirma que:

A identidade cultural ou social é o conjunto dessas características pelas quais os grupos sociais se definem como grupos: aquilo que eles são, entretanto, é 
inseparável daquilo que eles não são, daquelas características que os fazem diferentes de outros grupos.

Os estudantes surdos possuem suas identidades pautadas, principalmente, na sua forma de comunicação diferenciada. Isso não quer dizer que os surdos tenham uma cultura totalmente distinta da chamada cultura ouvinte, mas sua própria natureza é visuo-gestual.

Entende-se que o grupo de surdos possui características particulares, mesmo que não seja um grupo homogêneo. Perlin (1998) identifica alguns tipos de identidades surdas, mais complexas e diversificadas. Existem surdos filhos de pais surdos, surdos que não têm contato com a comunidade surda, surdos que não dominam a Língua de Sinais, dentre outros. Os professores precisam conhecer as identidades dos seus alunos para realizarem uma prática significativa.

Sabendo-se da relação intrínseca entre educação e cultura, há nas escolas um caráter, em geral, padronizador, homogeneizador e monocultural. Torna-se necessário romper com esse caráter e construir práticas educativas em que as questões da diferença e do multiculturalismo se façam cada vez mais presentes. Se as diferenças são mascaradas, há uma tendência em apagá-las, como se "por serem todos alunos, são todos iguais" (CANDAU, 2008).

Apesar de, atualmente, as escolas privilegiarem práticas homogeneizadoras que ignoram a questão da diferença e do multiculturalismo, o ensino de Geografia apresenta possibilidades de construção e respeito às identidades culturais de todos os alunos, inclusive dos estudantes surdos. Sendo a escola um lugar de encontro de culturas, de saberes científicos e de saberes cotidianos, a Geografia escolar é uma das mediações por meio das quais o encontro e o confronto entre culturas se dão (CAVALCANTI, 2005).

Para que as mudanças ocorram, os professores de Geografia deverão ser críticos e reflexivos, capazes de elaborar sua própria prática, propor mudanças e agir de forma autônoma no contexto social. 
Segundo Mellowki; Gauthier (2004, p.542) é "aos professores que cabe o trabalho de escolher e esse esforço de interpretação, de crítica e de contextualização dos referentes culturais em benefício da formação intelectual dos alunos". Desse modo, os professores de Geografia podem reconhecer as diferentes identidades, para pensar a prática pedagógica de uma forma que atenda melhor aos alunos surdos. Para oferecer um atendimento adequado a esses alunos, o professor necessita perceber a surdez como uma característica peculiar de uma pessoa, que não a impede de ser, de viver em sociedade, de estar envolvida com a comunidade em todas as suas atividades.

O ensino de Geografia pode proporcionar a socialização entre os alunos, por meio de relatos sobre a construção de suas identidades culturais, orientados a identificar as raízes culturais das famílias, do próprio contexto de vida, valorizando-se as diferentes características e especificidades de cada pessoa e grupo. Nessa perspectiva, o professor de Geografia tem um papel de mediador na construção de relações interculturais, também entre os alunos surdos e alunos ouvintes.

Em se tratando da aprendizagem dos estudantes surdos, o desenvolvimento cognitivo de uma criança surda se estrutura tendo por base informações visuais. A imagem e a experiência são fundamentais para que haja aprendizagem e, consequentemente, evolução e desenvolvimento (SILVA; BARAÚNA, 2007).

Os conceitos geográficos precisam ser explorados por meio de uma articulação do conteúdo com a realidade, sendo fundamental proporcionar situações de aprendizagem que valorizem as referências dos alunos quanto ao espaço vivido e produzido. É indicado trabalhar com os seus conhecimentos prévios, de forma construtivista.

Do mesmo modo, a prática de abordagens pedagógicas baseadas na visualização é promissora, pois os recursos visuais facilitam o aprendizado dos 
alunos surdos e podem fazer a ponte entre os conhecimentos cotidianos e científicos.

Os estudantes surdos, assim como os estudantes ouvintes, são estimulados pelos artefatos tecnológicos. Nesse sentido, o projetor multimídia, a TV, a Internet, o vídeo e o celular smartphone são recursos que motivam os alunos surdos e os demais alunos a aprenderem, pois são tecnologias que podem associar imagens e palavras escritas, além de ter a capacidade de projetar outras realidades, tempos e espaços.

A Internet é um recurso dinâmico, atraente, atualizado, que possibilita o acesso a um número ilimitado de informações sendo, portanto, um ótimo meio para se aprender Geografia. Se possível, os computadores da escola devem ser utilizados frequentemente, pois os alunos são despertados para a pesquisa individual na Internet, em que há ainda uma possibilidade de adaptação ao ritmo pessoal de cada aluno. A aprendizagem passa a ser cooperativa, pois os alunos buscam informação e trocam resultados com o grupo.

De informador, o professor passa a ser orientador, gerenciando as diversas informações acessadas na Internet, as quais precisam ser analisadas, discutidas e transformadas em conhecimento (MORAN, 2000).

O uso de imagens no ensino de Geografia para estudantes surdos é amplo e bastante aconselhável, pois podem ser utilizadas fotos, gravuras, desenhos, assim como maquetes. Dentro do assunto estudado, os alunos podem elaborar suas próprias imagens, por meio da criação dessas, ou ainda pesquisar em casa e trazer para sala de aula. Ao construir imagens e maquetes, os estudantes surdos poderão materializar uma dada realidade, refletir sobre a mesma e elaborar representações com as quais exercerá a leitura e, posteriormente, sua interpretação (PENA; SAMPAIO, 2011).

O uso do mapa no cotidiano das aulas de Geografia também é importante e aconselhável, pois auxilia nas análises e desenvolve habilidades de observação, 
manuseio, reprodução, interpretação, correção e construção de mapas (CAVALCANTI, 2005).

O Trabalho de Campo contribui para a organização dos raciocínios geográficos, tendo em vista que "a prática efetiva do Trabalho de Campo como metodologia de ensino na escola bilíngue possibilitará aos sujeitos surdos a problematização, análise, observação e registro dos fenômenos no espaço geográfico" (DE LA FUENTE, 2012, p.100).

Trabalhando com textos, também é interessante a elaboração de mapas conceituais, tanto pelos alunos quanto pelos professores, fazendo-se esquemas, fluxogramas, organogramas, dentre outros. Os mapas conceituais auxiliam os alunos surdos a compreenderem melhor textos longos, que podem ser de difícil interpretação devido à falta de entendimento da Língua Portuguesa.

Por fim, destaca-se que os recursos visuais precisam ser explorados como um recurso para desenvolver uma relação de diálogo em Libras, entre aluno e professor, e não como um fim, ou seja, não devem substituir a interação comunicativa em língua de sinais (SILVA, 2003).

\section{A REALIDADE DO ENSINO DE GEOGRAFIA NAS ESCOLAS COM SURDOS}

Na perspectiva da inclusão escolar de alunos com deficiência, o município de Uberlândia-MG desenvolve, desde o ano de 1991, programas educacionais que buscam atender às necessidades educacionais especiais dos estudantes surdos, sob coordenação da equipe do Centro Municipal de Estudos e Projetos Educacionais Julieta Diniz (Cemepe), por meio do Núcleo de Apoio às Diferenças Humanas (NADH).

Com o intuito de incluir o aluno com deficiência nas escolas comuns, o Cemepe implantou o Atendimento Educacional Especializado (AEE) em escolas da Prefeitura Municipal de Uberlândia; oferece cursos de formação aos profissionais da Educação Básica, incluindo a Educação Infantil, na perspectiva da Educação 
Especial; e também busca oferecer ao professor e à escola suportes para a sua ação pedagógica junto aos alunos com deficiência, incluindo a contratação de intérpretes e instrutores de Libras.

Apesar dos esforços exercidos pela Prefeitura Municipal de Uberlândia, sabe-se que investigações e intervenções constantes são necessárias para que os estudantes surdos não sejam apenas inseridos nas escolas, mas também permaneçam nestas, obtendo sucesso em sua escolarização. Para se conhecer a realidade da inclusão dos estudantes surdos, realizaram-se entrevistas semiestruturadas com onze professores de Geografia de sete escolas municipais de Uberlândia/MG (identificados por meio de siglas durante este artigo, para a preservação de suas identidades), as quais atendem o total de 32 estudantes surdos. Buscou-se conhecer as suas percepções acerca da inclusão escolar dos estudantes surdos e do ensino de Geografia para esses estudantes. Realizaramse, também, observações de aulas de Geografia, a fim de se conhecer as relações e a forma como ocorrem o ensino e a aprendizagem de Geografia na sala de aula.

Com relação à formação docente dos professores de Geografia, sabe-se que, a partir do aumento significativo de alunos com deficiência matriculados nas escolas comuns, tornou-se fundamental uma formação capaz de atender às diferenças de todos os alunos.

Sobre os estudantes surdos, a maioria dos professores entrevistados afirmou não ter sido formada para lecionar para esse alunado durante o curso de Geografia (91\%). Apenas um professor, formado há 28 anos, disse que, durante o seu estágio supervisionado, houve uma formação que o permitiu ministrar aulas para todos os alunos, independentemente de suas diferenças. Entretanto, não houve a participação em uma formação específica para atender estudantes surdos.

Apesar de a Libras ter sido inserida como disciplina curricular obrigatória nos cursos de formação de professores para o exercício do magistério, em nível 
médio e superior, por meio do Decreto $n^{\circ}$ 5.626, de 22 de dezembro de 2005, nem mesmo os professores formados mais recentemente a cursaram.

Na perspectiva da formação continuada, o Cemepe oferece cursos que dão a oportunidade de qualificação profissional aos educadores da Rede Municipal de Ensino. Dentre os cursos oferecidos, havia os cursos de Libras Básico e Intermediário. Dos onze professores de Geografia entrevistados, apenas quatro realizaram o curso de Libras Básico. Entretanto, afirmaram que dominam alguns sinais de Libras, sem conseguir uma comunicação satisfatória com os estudantes surdos.

O desconhecimento da Libras reflete nas sensações dos professores de Geografia ao terem conhecimento de que iriam ministrar aulas para estudantes surdos. Durante a entrevista, a maioria dos professores (37\%) disse que a primeira sensação foi a preocupação com a dificuldade de comunicação com os estudantes surdos. Uma professora respondeu: “Fiquei assustada, como iria me comunicar? Não tinha intérprete de Libras e havia muitos surdos" (GEO2). Além da dificuldade em não possuir intérprete na sala de aula, a ausência de comunicação direta com os estudantes surdos também foi motivo de preocupação por parte dos professores entrevistados, tendo em vista que a mediação por parte do intérprete de Libras ocorre em todas as ocasiões.

Outra professora disse que se preocupou com a comunicação com os alunos surdos, mas que não rejeitou a situação, como fazem alguns professores. De acordo com as entrevistas, em algumas ocasiões os professores não se sentem preparados e, estando cientes que a educação dos alunos surdos não depende somente deles, tendem a rejeitar os alunos com deficiência, ignorando suas necessidades especiais.

Consideraram normal ter estudantes surdos 27\% dos entrevistados: o professor GEO3a disse que “já era esperado"; a professora GEO4b afirmou que "é normal, pois preciso me adaptar"; e a professora GEO6 disse ser normal, pois sua primeira aluna surda foi no ano de 2002, sem intérprete. 
O sentimento de falta de preparo, ou ausência de formação adequada, foi experimentado por dois professores: GEO3b e GEO7b.

A professora GEO4a afirmou: "Fiquei surpresa, pois só descobri quando entrei na sala. Não há avisos no contrato ou na escola". Esse fato realmente ocorre nas escolas, pois no início do ano não se nota uma preocupação por parte da equipe pedagógica em informar e subsidiar os professores com relação aos alunos com deficiência. O mesmo ocorre com os professores que ingressam na escola, durante o ano letivo, por substituição ou desistência de algum outro professor.

Quanto às metodologias e materiais didáticos significativos para o ensino e aprendizagem de Geografia para alunos surdos, as opiniões dos professores entrevistados foram diversas. Os mesmos responderam aleatoriamente, sem direcionamentos por parte da pesquisadora. A figura 1 apresenta as suas opiniões, de acordo com a frequência com que foram citadas.

Figura 1 - Metodologias e materiais didáticos significativos de Geografia para surdos

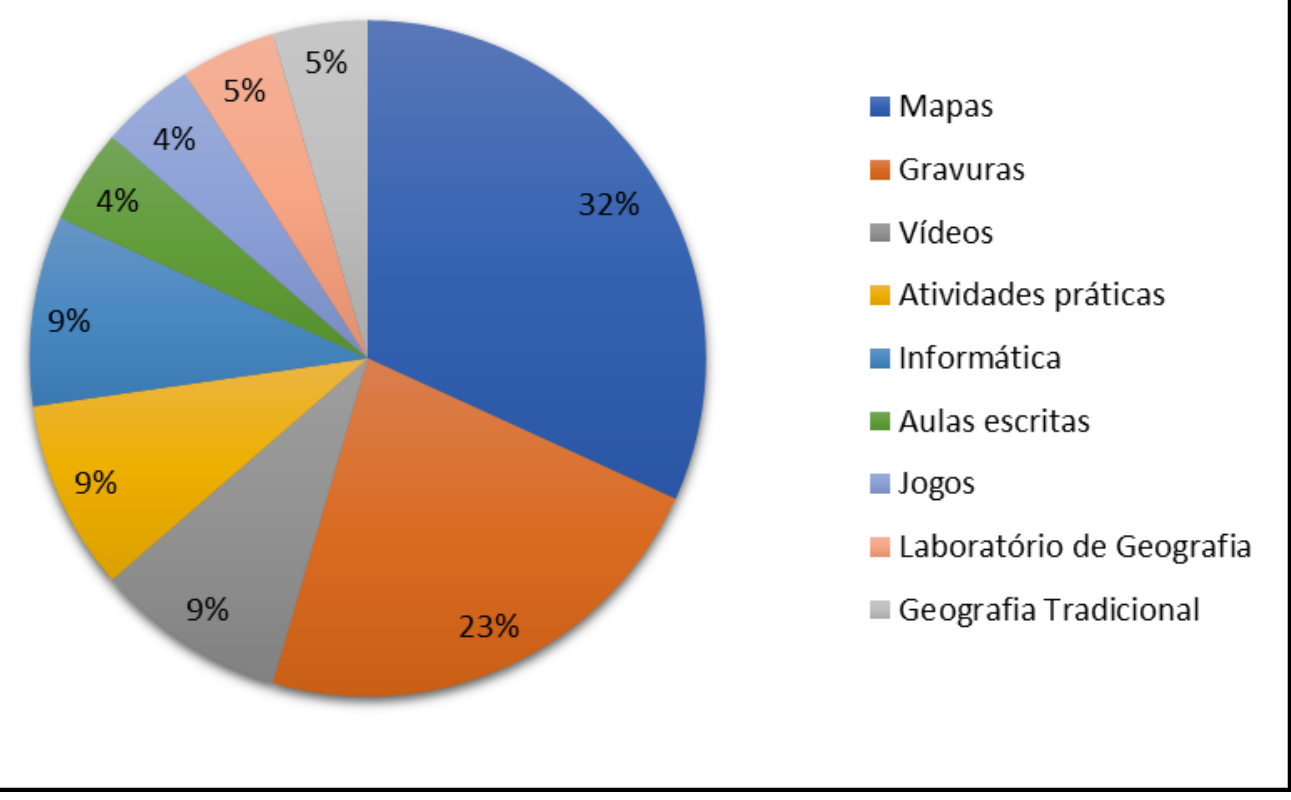

Fonte: Pesquisa realizada com 11 professores de Geografia de escolas com estudantes surdos em Uberlândia/MG, 2012. 
Conhecer as metodologias e os materiais didáticos que os professores consideram significativos para a aprendizagem dos alunos surdos pode fazê-los refletir se estão praticando em suas aulas aquilo que acreditam. Também podem ser alvo de pesquisa, pois, se eles não possuem uma formação adequada para atender alunos surdos, podem estar equivocados sobre suas opiniões e práticas pedagógicas.

Um exemplo é a concepção da professora GEO3b, a qual acredita que a Geografia Tradicional era o melhor caminho para a educação dos alunos surdos, por ser embasada na memorização e em respostas prontas.

A maioria dos professores enfatizou o uso de recursos visuais, como: informática, gravuras, revistas, gráficos, mapas, rochas, globo terrestre, vídeos e maquetes. Esses recursos são realmente propícios para um aprendizado mais significativo para os alunos surdos, pois favorecem o emprego da visão, muito expressiva e utilizada pelos sujeitos surdos.

De acordo com as orientações da Secretaria de Educação do Governo do Estado de Minas Gerais, "atividades e recursos visuais são indispensáveis e enriquecedores do processo de ensino-aprendizagem dos surdos" (MINAS GERAIS, 2007, p.8).

O trabalho com mapas foi citado por sete professores, o que exige uma formação cartográfica adequada para que esse recurso seja utilizado com sucesso. Atividades como colorir e memorizar nomes e localização de rios, cidades, capitais, estados, países e continentes não são significativas quando trabalhadas sem a contextualização com o conteúdo estudado. Como sugestão, pode-se trabalhar com imagens dos lugares estudados no mapa e explorar os seus aspectos físicos e humanos.

Apesar de o questionamento ter sido direcionado para metodologias e materiais didáticos de Geografia, três professores destacaram a importância do intérprete de Libras durante as atividades. 
Sabendo-se que os recursos visuais são importantes aliados na educação dos estudantes surdos, os professores de Geografia entrevistados responderam se os utilizam ou não em suas aulas e, quando utilizados, quais são esses recursos, conforme figura 2.

\section{Figura 2 - Os professores de Geografia utilizam recursos visuais?}

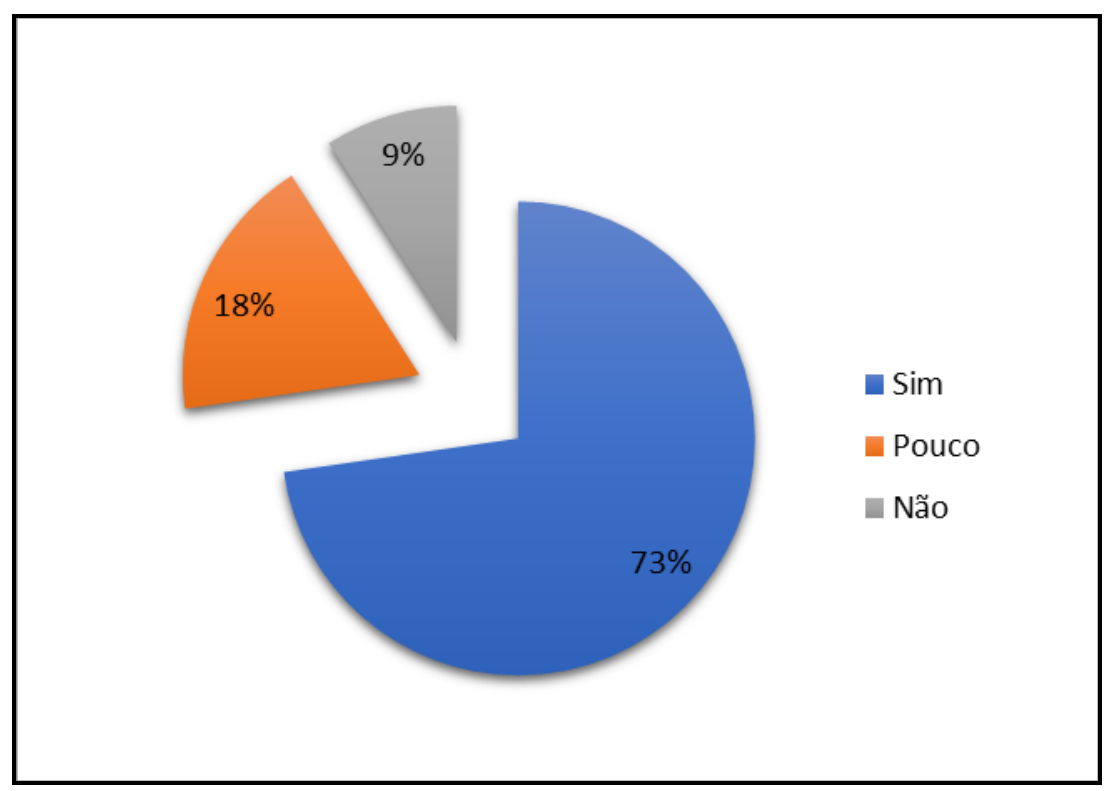

Fonte: Pesquisa realizada com 11 professores de Geografia de escolas com estudantes surdos em Uberlândia/MG, 2012.

Segundo as respostas dos professores, a maioria utilizava recursos visuais, o que pode ser muito promissor na educação dos surdos. O recurso visual mais citado pelos professores foi o mapa, utilizado por sete professores. Também eram utilizados o atlas e o globo terrestre. A informática foi o segundo recurso mais citado, sendo utilizada por seis professores. Nesse recurso, foram mencionadas as pesquisas na Internet, feitas pelos alunos em casa ou com a utilização do laboratório de informática, e o Datashow.

A Internet é uma ferramenta que os alunos surdos se interessam muito, pois, geralmente, é por ela que eles se comunicam com os amigos surdos, por meio do bate-papo virtual. Desse modo, a maioria dos estudantes surdos tem interesse em utilizá-la, estando em contato com informações diversas, imagens, 
vídeos e conhecimentos gerais. O Datashow, apesar de ser pouco utilizado, também é muito interessante, pois permite ao professor elaborar slides com várias imagens, esquemas, vídeos e resumos, de modo que tanto os alunos surdos quanto os alunos ouvintes tenham uma aula mais interessante e significativa.

O vídeo foi um recurso utilizado por cinco professores de Geografia. Os filmes e documentários eram explorados, na perspectiva de complementar as temáticas estudadas nas aulas.

O professor precisa estar atento para que os vídeos apresentados possuam legenda e para que os alunos surdos estejam conseguindo visualizá-las. O intérprete deve permanecer durante a apresentação desse recurso, pois, geralmente, o estudante surdo não consegue interpretar todas as informações apresentadas na legenda, devido ao vocabulário extenso da Língua Portuguesa e ao seu pouco contato com esta, tendo em vista que, ao contrário dos ouvintes, possuem apenas a relação visual com essa língua. Nesse sentido, quando os alunos surdos possuírem alguma dúvida quanto ao entendimento do vídeo, devem ser instruídos a perguntar ao professor de Geografia, por intermédio do intérprete de Libras, enquanto o vídeo esteja em pausa.

Outros recursos visuais citados por professores foram: o livro didático, as fotos, as imagens, as cópias de xérox, os desenhos esquemáticos no quadro negro, os gráficos e as tabelas. Todos esses recursos são propícios a um melhor entendimento das aulas de Geografia, pois permitem explorar de diversas formas o conteúdo apresentado. Sua utilização requer que o professor esteja atento para oferecer ao aluno surdo momentos de observação e análise individuais e outro momento de explicação. Os alunos ouvintes são capazes de observar os recursos juntamente com uma explicação oral; entretanto, os alunos surdos, por possuírem, nesse momento, apenas o canal visual-gestual, precisam visualizar a explicação em Libras, feita pelo intérprete dessa língua, separadamente da observação do recurso. Aconselha-se que, primeiramente, o surdo leia o texto no 
quadro ou impresso e/ou faça a observação de imagens e materiais concretos, para posteriormente observar a sua sinalização.

A maioria dos professores de Geografia entrevistados (82\%) acreditava que os alunos surdos se mostravam mais propícios à aprendizagem a partir dos recursos visuais. A professora GEO3b disse que às vezes eles se interessavam e a professora GEO4b disse não ter observado. Essa constatação confirma o interesse que os alunos surdos apresentam pelos recursos visuais, evidente nos estudos da área.

Com relação às avaliações dos alunos, todos os professores entrevistados (100\%) utilizavam as avaliações escritas, a participação na sala de aula e as pesquisas em casa. As avaliações escritas realizadas pelos alunos surdos eram as mesmas dos alunos ouvintes. A diferença estava em sua aplicação, pois havia a participação do intérprete de Libras, o qual interpretava a prova escrita na Língua Portuguesa, traduzindo-a para a Libras.

O intérprete deve traduzir todas as questões da avaliação - do Português escrito para a Língua de Sinais - sem acréscimo de esclarecimentos, adendos, exemplificações ou demais auxílios, pois eles, quando necessários, dizem respeito somente ao professor. (MINAS GERAIS, 2007, p.16)

Conforme a citação anterior, os alunos surdos possuem o direito de ter suas avaliações interpretadas em Libras, desde que o intérprete não interfira no entendimento ou nas respostas das questões, restringindo-se à compreensão da Língua Portuguesa.

Também com relação às avaliações escritas,

Os surdos possuem, devido à falta de ensino adequado do Português como segunda língua, dificuldades de leitura, compreensão e escrita da Língua Portuguesa. É essencial que o professor considere essa diferença linguística (MINAS GERAIS, 2007, p. 9).

Dessa forma, os professores de Geografia precisam avaliar de modo diferenciado as respostas dos alunos surdos, considerando os conhecimentos expostos e não a estrutura gramatical das frases. Nesse momento, o intérprete pode esclarecer e acompanhar a correção das avaliações e a leitura dos textos 
dos alunos, mediante solicitação. A avaliação em Libras também deve ser uma opção.

Na citação abaixo apresenta-se um texto muito característico das pessoas surdas, elaborado por uma estudante do $1^{\circ}$ ano do Ensino Médio, modalidade de Educação de Jovens e Adultos (EJA), com idade de vinte e um anos. No texto, foi solicitado pela professora do AEE que a aluna informasse sobre o seu dia a dia. Para que a identidade dessa aluna fosse preservada, o seu nome foi alterado.

A Thais cedo 05:20 acordar precisar antes arrumar, escova de dente, escova de cabelo. 06:00 antes chegar ponto de ônibus, terminal central 06:35 ônibus 101 amarelo dia segunda até sexta. Sábado casa avó talvez Domingo.

A escola veio precisar aprender. Professora atenção alunos precisar. Estudar é Escola aprender. Gostar escola bom precisar estudar. Gostar escola alunos muito.

As professoras muito matéria tudo precisar aprender. Conseguir passar de escola tudo azul.

Observa-se que a aluna compõe o seu texto de acordo com a estrutura dos sinais de Libras, sem a utilização de preposições e, em parte, de modo discordante da gramática da Língua Portuguesa. Cada aluno surdo apresentará um nível diferenciado de desenvolvimento desta língua, estando mais próximo ou mais distante da escrita das pessoas ouvintes. Todos os sujeitos surdos, até mesmo os mais estudiosos, terão em seus textos uma particularidade na forma de escrita, devido a sua língua natural possuir uma estrutura gramatical diferenciada. Cabe aos professores e demais pessoas que tenham contato com esses textos conhecer a forma de escrita surda e respeitá-la.

Com relação aos grupos de trabalho, os surdos, geralmente, não conseguem realizar trabalhos com os alunos ouvintes quando há mais de três alunos surdos em uma mesma turma. Por ser apenas um intérprete de Libras por sala de aula, esse profissional não consegue acompanhar mais de um grupo com surdos para realizar a comunicação entre esses e os alunos ouvintes, e ainda a interpretação das explicações do professor. A dificuldade de comunicação faz com que os alunos surdos fiquem, geralmente, no mesmo grupo de trabalho. 
Comparando os alunos, a maioria dos professores acreditava que havia diferença entre os alunos surdos e os alunos ouvintes para aprender Geografia. O professor GEO5 afirmou que "o aluno ouvinte tem mais possibilidades de acesso à comunicação e informação", o que facilita o aprendizado da Geografia a partir dos exemplos e atualidades. De fato, os sujeitos ouvintes são mais privilegiados por estarem inseridos em uma comunidade cuja forma de comunicação majoritária é a Língua Portuguesa oral-auditiva. Desde crianças, estão em contato com essa língua, principalmente por meio de seus familiares e mídias, obtendo conhecimentos diversos. Em contrapartida, os sujeitos surdos geralmente nascem em famílias ouvintes que não utilizam a Libras. As emissoras de televisão, de modo geral, não se preocupam em interpretar sua programação em Libras. Desse modo, os surdos perdem muitas informações cotidianas, principalmente quando não dominam a Língua Portuguesa escrita.

Os demais professores citaram como diferença dos alunos surdos: a impossibilidade de se trabalhar com músicas e vídeos (GEO4a); a dificuldade com a Língua Portuguesa escrita (GEO6); e a necessidade de tempo maior para a compreensão dos conteúdos (GEO3a).

Outro assunto abordado durante as entrevistas foi o apoio oferecido, por parte da equipe pedagógica, para que os professores de Geografia ministrassem aulas para os alunos surdos. A relação com os professores do AEE e com os intérpretes de Libras também foi discutida.

De acordo com os professores, a equipe pedagógica da escola (supervisão e especialistas) não oferecia informações e suporte para ensinar alunos surdos. A professora GEO3c informou que "não há tempo" para essa troca de informações. O professor GEO6 disse que o auxílio era vindo principalmente da intérprete de Libras, a qual orientava sobre as atividades que eram mais interessantes e informava as peculiaridades dos alunos surdos. A professora GEO4b e o professor GEO1 citaram o AEE como único suporte oferecido para o atendimento dos alunos surdos. 
Esse fato contradiz o que é proposto nas orientações do Governo do Estado de Minas Gerais, o qual expõe que "é importante que a escola busque e ofereça regularmente aos professores informações sobre a especificidade dos surdos e o seu processo de inclusão educacional" (MINAS GERAIS, 2007, p.7). Seguindo essa orientação, a escola deveria contribuir significativamente com o trabalho do professor de Geografia e a aprendizagem do aluno surdo.

Em todas as escolas municipais, cujos professores de Geografia entrevistados atuam, é oferecido o Atendimento Educacional Especializado, sendo que todos os seus alunos surdos o frequentam.

Com relação às maiores contribuições do AEE para os estudantes surdos, a maioria dos professores de Geografia acreditava que fosse o esclarecimento da matéria estudada na sala de aula e a revisão do conteúdo para as atividades avaliativas. O trabalho diferenciado com professores especialistas também foi citado como uma grande contribuição, assim como apontou a professora GEO4a: "O atendimento é feito de maneira personalizada. Os professores do AEE pedem o material e focam nas avaliações para os alunos passarem de ano".

De acordo com a afirmação da professora, durante o AEE a preocupação maior não era com a aprendizagem significativa dos estudantes surdos, mas com o sucesso nas avaliações escolares.

O professor GEO5 acreditava que os alunos surdos aprendiam novos sinais e contextualizam conteúdos que não entenderam na sala de aula. A professora GEO3b não soube informar quais são as contribuições, por não possuir relação com esse atendimento e desconhecer o modo como era realizado o trabalho. A professora GEO4b foi a única professora que destacou que havia orientação, por parte dos professores do AEE, de como trabalhar com os estudantes surdos.

De modo geral, observou-se que os professores de Geografia acreditavam que o AEE era oferecido como forma de reforço escolar, onde os estudantes surdos realizavam as atividades de sala de aula, os trabalhos avaliativos e faziam revisões para as provas. Essa concepção precisa ser mudada, pois o AEE realiza 
um trabalho que busca a formação do aluno, visando à sua autonomia na escola e fora dela.

Art. $2^{\circ}$. O AEE tem como função complementar ou suplementar a formação do aluno por meio da disponibilização de serviços, recursos de acessibilidade e estratégias que eliminem as barreiras para sua plena participação na sociedade e desenvolvimento de sua aprendizagem (BRASIL, 2009).

Nesse sentido, o professor do AEE, dentre as suas atribuições, possui a função de oferecer metodologias e materiais didáticos complementares para o ensino de Geografia, na perspectiva de auxiliar o entendimento dos conteúdos ministrados na sala de aula.

Indagados se possuíam relação com o Atendimento Educacional Especializado, sete professores de Geografia entrevistados (64\%) disseram que não. Esse fato é preocupante, pois os profissionais do AEE possuem formação especializada, capaz de subsidiar os professores da sala de aula comum em suas dúvidas e demandas. Também são os professores do AEE que atendem, de forma individualizada, os alunos surdos, sendo capazes de conhecer as necessidades e potencialidades mais específicas desses alunos e compartilhá-las com os demais profissionais.

O professor GEO6 afirmou que possuía pouca relação, apenas durante os conselhos de classe e no início do ano, quando passavam o histórico dos alunos com deficiência. A professora GEO4b informou que tinha relação, mas que essa poderia ser melhor se houvesse mais tempo de conversar e se informar sobre os alunos. A professora GEO4a também disse haver uma certa relação, mas somente quando havia solicitação de informações sobre trabalhos avaliativos e provas.

De acordo com o que foi exposto, acredita-se que algumas atribuições do professor do Atendimento Educacional Especializado, presentes nas Diretrizes Operacionais para o Atendimento Educacional Especializado na Educação Básica, modalidade Educação Especial (BRASIL, 2009), não estão sendo realizadas nas escolas. Dentre elas, encontra-se, no artigo 13: 
VIII - estabelecer articulação com os professores da sala de aula comum, visando à disponibilização dos serviços, dos recursos pedagógicos e de acessibilidade e das estratégias que promovem a participação dos alunos nas atividades escolares.

Percebe-se que não havia no ambiente escolar um tempo exclusivo para que o professor da sala de aula comum se reunisse com o professor do AEE. Os horários de trabalho eram diferenciados, visto que O AEE era realizado no contraturno. Apenas teriam contato direto os professores que trabalhavam em dois períodos, coincidindo os horários.

Por fim, os professores de Geografia informaram o que acreditavam que deveria ocorrer para que os alunos surdos se desenvolvessem melhor nas escolas comuns. A figura 3 representa as informações obtidas.

A presença constante do intérprete de Libras na sala de aula foi a mais assinalada para o desenvolvimento e aprendizado dos alunos surdos (21\%). A capacitação desse profissional é imprescindível, pois o seu trabalho está diretamente relacionado com o sucesso do surdo na escola comum. É necessária a disponibilização de cursos de aperfeiçoamento em Libras, para que haja um maior conhecimento sobre os sinais utilizados, assim como a sua padronização.

A capacitação dos professores, incluindo o aprendizado da Libras, também foi informada por quatro entrevistados. Essa capacitação deve ser considerada na formação inicial e na formação continuada. Para os professores de Geografia em exercício, devem ser dadas condições de frequentarem os cursos de Libras e de formação para a inclusão de alunos surdos, abrangendo a pesquisa e a elaboração de materiais didáticos, preferencialmente no mesmo turno em que trabalham na escola municipal, pois muitos atuam em mais de uma escola, em horários diversos. 
Figura 3 - O que deve ocorrer para que os alunos surdos se desenvolvam mais nas escolas comuns?

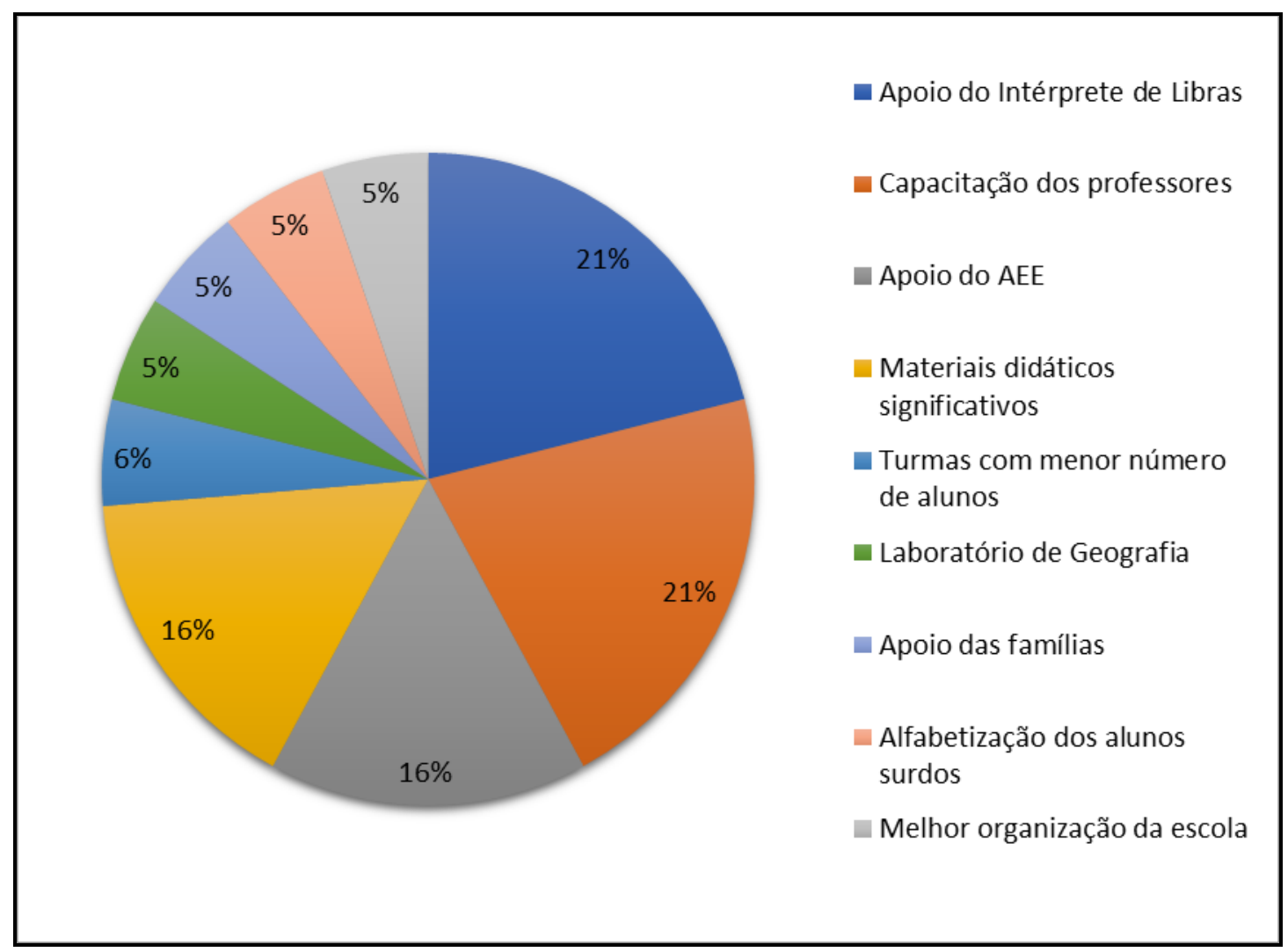

Fonte: Pesquisa realizada com 11 professores de Geografia de escolas com estudantes surdos em Uberlândia/MG, 2012.

A necessidade de aproximação entre o AEE e os professores da sala de aula comum foi apontada por três professores. Com as informações obtidas nas entrevistas, observou-se que há um distanciamento desse atendimento com a sala de aula comum.

A existência e a utilização de materiais didáticos significativos para os alunos surdos foram especificadas por três professores de Geografia. Sugeriu-se que o Cemepe proporcionasse, além dos cursos de Libras, oficinas práticas para a confecção de materiais didáticos e para a elaboração de metodologias diferenciadas para o ensino de alunos surdos. Outra questão é a falta de recursos tecnológicos que algumas escolas ainda enfrentam, sem a disponibilidade de microcomputadores para os alunos e Datashow. 
Com relação às turmas com menor número de alunos, a orientação SD nº 01/2005 afirma que a escola comum, cujas turmas sejam compostas de alunos sem e com deficiência e condutas típicas, deve possuir de vinte a vinte e cinco alunos por turma. Pode haver até três alunos com necessidades especiais semelhantes em cada turma e até quinze alunos surdos por turma, com a alocação de um intérprete por turma (MINAS GERAIS, 2005). Se os professores conhecessem essa orientação, poderiam exigir que suas turmas compostas de alunos surdos e ouvintes tenham, no máximo, vinte e cinco alunos, pois essa regra não é seguida.

A implementação de laboratório de Geografia, sugerida pela professora GEO4b, certamente contribui significativamente com a educação dos alunos surdos. Nesse espaço, é possível utilizar materiais concretos, como mapas diversos, atlas, globo terrestre, imagens, rochas, assim como computador, Datashow e vídeo.

O apoio das famílias é imprescindível para todo o trabalho escolar realizado com os alunos surdos. Sabendo-se que inúmeros pais não dominam a Libras e não realizam uma boa comunicação com seus filhos surdos, a ajuda do instrutor de Libras, cuja função é, dentre outras, oferecer cursos dessa língua na escola, pode ser a chave para uma melhor relação das famílias com a escola e professores.

A alfabetização dos alunos surdos também é fundamental para o aprendizado de Geografia e de todas as disciplinas escolares, assim como o desenvolvimento pleno do surdo no âmbito escolar. Nesse sentido, sabe-se que o AEE pode propiciar três momentos didático-pedagógicos: o Atendimento Educacional Especializado em Libras (realizado por um professor ouvinte que domine essa língua, para esclarecer alguns conteúdos escolares), o Atendimento Educacional Especializado para o ensino de Libras (oferecido pelo instrutor surdo para o aprendizado dessa língua), e o Atendimento Educacional Especializado para o ensino da Língua Portuguesa (BRASIL, 2010). Nesse último momento, o 
aluno surdo será orientado por uma professora de Língua Portuguesa, desenvolvendo sua competência linguística e textual, por meio da concepção bilíngue.

Para uma melhor organização da escola, citada pela professora GEO4a, torna-se necessário o apoio da Superintendência Regional de Ensino (SRE) e do Núcleo de Apoio às Diferenças Humanas (NADH), presentes em Uberlândia. Esses órgãos deveriam acompanhar o desenvolvimento da Educação Especial nas escolas, organizando o Serviço de Apoio à Inclusão. Toda a equipe pedagógica precisa conhecer as peculiaridades dos alunos surdos e se unir para trocar ideias e informações de práticas pedagógicas mais eficientes.

As sugestões apontadas pelos professores de Geografia são muito válidas para a melhoria do ensino e da aprendizagem dos alunos surdos na escola comum. Acredita-se que todas elas são oportunas de serem realizadas, principalmente por meio do apoio dos dirigentes escolares e das superintendências regionais de ensino.

A legislação vigente garante um vasto suporte aos professores da sala de aula, apesar de eles não terem sido contemplados com uma formação inicial adequada. Conhecer e exigir a execução dos direitos e recursos constantes nos documentos oficiais torna-se fundamental para que as melhorias ocorram.

\section{CONSIDERAÇÕES FINAIS}

Os estudantes surdos possuem uma diferença linguística e cultural que não os impede de terem sua inserção social e educacional. O ensino de Geografia apresenta possibilidades de construção e respeito às identidades culturais de todos os alunos, inclusive dos alunos surdos. Sendo a escola um lugar de encontro de culturas, de saberes científicos e de saberes cotidianos, a Geografia escolar é uma das mediações por meio das quais o encontro e o confronto entre culturas se dão. Apesar de, atualmente, as escolas privilegiarem práticas 
homogeneizadoras que ignoram a questão da diferença e das culturas diversas, os professores de Geografia apresentam possibilidades de construção e respeito às identidades culturais de todos os alunos, inclusive dos alunos surdos.

A pesquisa concluiu que a maioria dos professores de Geografia não tem sido formada para lecionar aulas para estudantes surdos. De modo geral, os professores não faziam uso da Libras, ou seja, não conseguiam se comunicar com seus alunos surdos. A maior preocupação desses professores estava relacionada à dificuldade de comunicação e à falta de preparo, o que, de fato, reflete negativamente no ensino, pois os alunos surdos sentiam-se frustrados e incomodados por não conseguirem ser compreendidos pelos professores quando não havia a mediação do intérprete.

A inclusão da Libras como disciplina curricular obrigatória nos cursos de formação de professores foi um avanço para a escolarização das pessoas surdas e, também, para o fortalecimento e reconhecimento da Libras como língua natural da comunidade surda brasileira. Todavia, também há a necessidade de instrumentalizar professores já atuantes na escola comum para a inclusão de alunos com deficiência. Os cursos de Libras e de metodologias para estudantes surdos precisam ser oferecidos em horários flexíveis, de preferência, durante os módulos escolares, no âmbito escolar.

Sabendo-se que os estudantes surdos precisam ser percebidos como sujeitos que possuem o canal visual-gestual como forma de comunicação e a Libras como primeira língua, o ensino de Geografia deve ser recorrente às práticas pedagógicas baseadas na visualização, pois os recursos visuais facilitam o aprendizado dos estudantes surdos e podem fazer a ponte entre os conhecimentos cotidianos e científicos. Os artefatos tecnológicos, a Internet, os mapas conceituais, o uso de imagens, de mapas e maquetes, assim como a realização de Trabalho de Campo são promissores.

A maioria dos professores de Geografia pesquisados utilizava recursos visuais. Os entrevistados também afirmaram que os estudantes surdos se 
interessavam mais pelas aulas e pelo conteúdo quando eram utilizados esses recursos. Sendo o mapa frequentemente utilizado durante as aulas, há a necessidade de uma formação cartográfica adequada para que esse seja explorado com sucesso.

É válido ressaltar que os recursos visuais, quando dissociados de explicações e aprofundamentos teóricos, não contribuem significativamente com a aprendizagem dos estudantes, pois não conseguem atingir os objetivos propostos pela aula. É necessária a explicação em Libras sobre o tema estudado e a descrição dos conteúdos apresentados.

Durante as observações das aulas, foi notável que os estudantes surdos apresentavam interesse em Geografia de acordo com a postura adotada pelo professor. Se o professor conhecesse as peculiaridades desses alunos, trabalhasse com recursos visuais e desenvolvesse atividades atrativas, o interesse então seria despertado. Caso contrário, se a aula for enfadonha e/ou não exigir esforço por parte dos alunos, eles não demonstravam interesse em aprender esse conteúdo.

Para o sucesso escolar dos estudantes surdos, é necessário também desmitificar a crença de que esses estudantes possuem um déficit cognitivo, ou que são menos capazes do que as pessoas ouvintes. Quando o professor não acredita que o aluno seja capaz de aprender, não irá se esforçar para oferecer metodologias de ensino e materiais didáticos mais significativos. Cabe aos cursos de graduação e formação continuada, aos professores do AEE e, também, aos intérpretes de Libras informarem as peculiaridades e potencialidades dos estudantes surdos, difundindo as concepções do conceito socioantropológico de surdez.

Os professores precisam ser esclarecidos sobre as funções do intérprete de Libras, assim como sobre a necessidade de um trabalho conjunto que favoreça a aprendizagem do estudante surdo. Muitos professores transferem para os 
intérpretes de Libras, de forma errônea, a função de ensinar, monitorar e disciplinar os estudantes surdos.

Com relação ao Atendimento Educacional Especializado, os professores de Geografia acreditavam que ele era oferecido como forma de reforço escolar, em que os estudantes surdos realizavam as atividades de sala de aula, os trabalhos avaliativos e faziam revisões para as provas. O professor do AEE, dentre as suas atribuições, possui a função de compartilhar metodologias e materiais didáticos complementares para o ensino de Geografia. Entretanto, isso não vem ocorrendo, pois a maioria dos professores de Geografia não tinha relação de trabalho com o professor do AEE. Observa-se a necessidade da criação de momentos em que esses profissionais possam dialogar e construir as alternativas para a melhoria do ensino dos estudantes surdos, com um trabalho em equipe.

Conclui-se que as demandas atuais mais urgentes para a inclusão escolar dos estudantes surdos são: a capacitação dos professores, incluindo o aprendizado da Libras; a aproximação entre o AEE e os professores da sala de aula comum; a presença constante do intérprete de Libras, bem habilitado, na sala de aula, assim como a pesquisa e a utilização de metodologias e materiais didáticos de Geografia significativos para esses estudantes.

Nesse aspecto, a realidade investigada em Uberlândia ilustra um paradoxo. A escola tem a intenção de incluir o estudante surdo e valorizar o uso da Libras. Entretanto, no momento em que ela o insere na sala de aula comum, composta de alunos surdos e alunos ouvintes que não sabem a Libras, com o professorado sem formação e sem um apoio pedagógico adequado, há, de fato, uma integração.

Não se trata de incluir para garantir o direito constitucional de igualdade educacional; a questão principal é garantir aos estudantes surdos o acesso e a permanência na escola, com qualidade educacional.

Caso essa realidade não seja transformada, os estudantes surdos continuarão sendo vítimas de uma cultura ouvintista, a qual privilegia as 
metodologias direcionadas para os estudantes ouvintes. Diante dessa realidade, a comunidade surda defende, cada vez mais, a implementação de escolas bilíngues para surdos, as quais possuem o compromisso com o ensino da Libras como língua principal, seguido pela compreensão da Língua Portuguesa escrita.

\section{REFERÊNCIAS}

BRASIL. Ministério da Educação. Secretaria de Educação Especial. Diretrizes Nacionais para a Educação Especial na Educação Básica. Brasília, MEC/SEESP, 2001.

BRASIL. Presidência da República. Decreto $\mathbf{n}^{\mathbf{0}} \mathbf{5 . 6 2 6}$, de 22 de dezembro de 2005. Regulamenta a Lei $n^{\circ}$ 10.436, de 24 de abril de 2002, que dispõe sobre a Língua Brasileira de Sinais - Libras, e o art. 18 da Lei no 10.098, de 19 de dezembro de 2000. Brasília, 2005.

BRASIL. Ministério da Educação. Conselho Nacional de Educação. Parecer CNE/CEB n¹3/2009. Diretrizes Operacionais para o atendimento educacional especializado na Educação Básica, modalidade Educação Especial. Brasília, 2009.

BRASIL. Ministério da Educação. Secretaria de Educação Especial. Universidade Federal do Ceará. A Educação Especial na Perspectiva da Inclusão Escolar. Brasília, 2010.

CALLAI, H. C. A formação do profissional da Geografia. ljuí: Ed. UNIJUÍ, 1999.

CANDAU, V. M. Multiculturalismo e educação: desafios para a prática pedagógica. In: MOREIRA, A.F.; CANDAU, V.M. Multiculturalismo: diferenças culturais e práticas pedagógicas. Petrópolis: Vozes, 2008. p.13-37.

CAVALCANTI, L. S. A formação de professores de Geografia: o lugar da prática de ensino. In: TIBALI, Elianda F. Arantes, CHAVES, Sandramara Matias (org.). Concepções e Práticas em formação de professores: diferentes olhares. Rio de Janeiro: DP\&A, 2003. p. 189-206.

CAVALCANTI, L. S. Geografia e práticas de ensino. Goiânia: Alternativa, 2005.

DE LA FUENTE, A.R.S. O trabalho de campo em Geografia: múltiplas dimensões espaciais e a escolarização de pessoas surdas. 2012. 160f. Dissertação (Mestrado em Geografia) - Universidade Federal de Uberlândia, Uberlândia, 2012. 
DUEK, V. P.; NAUJORKS, M. I. Docência e inclusão: reflexões sobre a experiência de ser professor no contexto da escola inclusiva. In: Revista da FAEEBA - Educação e Contemporaneidade, Salvador, v.16, n.27, jan./jun, 2007. p.41-54.

MELLOWKI, M.; GAUTHIER, C. O professor e seu mandato de mediador, herdeiro, intérprete e crítico. Educação \& Sociedade, Campinas, v.25, n.87, p. 537-571, maio/ago. 2004.

MICHELS, M. H. Gestão, formação docente e inclusão: eixos da reforma educacional brasileira que atribuem contornos à organização escolar. In: Revista Brasileira de Educação. v.11, n. 33, set./dez. 2006. p.406-414.

MINAS GERAIS. Secretaria de estado de Educação de Minas Gerais. A inclusão de alunos com surdez, cegueira e baixa visão na Rede Estadual de Minas Gerais: orientações para pais, alunos e profissionais da educação. Belo Horizonte: SEE/MG, 2007.

MORAN, J. M. Ensino e aprendizagem inovadores com tecnologias audiovisuais e telemáticas. In: MORAN, J. M. Novas tecnologias e mediação pedagógica. Campinas: Papirus, 2000. p. $11-65$.

PENA, F. S. Escolarização de pessoas surdas no contexto do ensino e aprendizagem de Geografia. 2010. Monografia (Curso de Geografia). 51p. Universidade Federal de Uberlândia, Uberlândia, 2010.

PENA. F. S.; SAMPAIO, A. A. M. Ensino e aprendizagem de Geografia para a educação inclusiva de surdos. In: Ler o mundo com as mãos e ouvir com os olhos: reflexões sobre o ensino de geografia em tempos de inclusão. Uberaba: Vitória, 2011. p. 207223.

PERLIN, G. T. T. Identidades surdas. In: SKLIAR, C. B. A surdez: um olhar sobre as diferenças. Porto Alegre: Mediação, 1998. p.51-73.

REIS, F. Professor surdo: a política e a poética da transgressão pedagógica. 2006. 121f. Dissertação (Mestrado em Educação) - Universidade Federal de Santa Catarina, Santa Catarina, 2006.

RODRIGUES, D. Dez ideias (mal) feitas sobre a educação inclusiva. In RODRIGUES, D. (org.). Inclusão e Educação - Doze olhares sobre a Educação Inclusiva. São Paulo: Summus Editorial, 2006. p. 299-318.

ROSA, D. E. G. R. Formação de professores: concepções e práticas. In: CAVALCANTI, L. S. Formação de professores: concepções e práticas em Geografia. Goiânia: Vieira, 2006. p.15-25. 
SILVA, B. C. Cenário armado, objetos situados: o ensino de Geografia na educação de surdos. 2003. 244 f. Dissertação (Mestrado em Geografia) - Universidade Federal do Rio Grande do Sul, Porto Alegre, 2003.

SILVA, L. C. da.; BARAÚNA, S. M. A inclusão escolar do surdo: algumas reflexões sobre um cotidiano investigado. In: Revista da FAEEBA - Educação e Contemporaneidade, Salvador, v. 16, n. 27, jan./jun., 2007. p. 56-67.

TARDIF, M. Saberes profissionais dos professores e conhecimentos universitários. Revista brasileira de Educação, n.13, jan./fev./mar./abr. 2000. p. 5-24. 